\title{
Зыбкий образ минувшего бытия, или работа с частноправовыми актами
}

\author{
Ольга Евгеньевна Кошелева \\ Институт всеобщей истории Российской Академии Наук \\ okosheleva@mail.ru
}

Рецензия на книгу: Дворяне Москвы: свадебные акты и духовные завещания петровского времени. Сост., очерки и коммент. Н.В. Козловой и А.Ю. Прокофьевой. Москва: Политическая энциклопедия, 2015. 911 с., ил.

Что такое частноправовые акты петровского времени? Не вдаваясь в долгие объяснения, приведу их примеры, чтобы читатель сразу получил представление, о чем далее пойдет речь. Выбираю из публикации кратчайшие тексты, отмечая при этом, что есть гораздо более обширные документы.

№ 47. Запись духовной стольника Юрия Кишкина.

Февраля в 3-ий день. Стольник Юрья Кишкин приказывает по разлучении души своей от тела поминовение творить и всем управлять жене своей Дарье Никитиной дочери. А после своего живота учинить ей, Дарье, взять святых образов восемь в окладе, крест серебреной Животворящей; да платья: два ковтана (кафтана - О.К.) суконные, два комзола; шесть книг печатных; поднос серебреной; да денег сто пятьдесят рублев; да порозжее место дворовое.

К той духовной он, Юрья, и свидетели: церкви Преображения Господня, что на Тверской, поп Тихон, подполковники Василий Стремоухов, Василей Титов, Сергей Секнотов, поручик Семеновского полку Петр Шелемов, капитаны Иван Чюпахин, Андрей Наумов - руки приложили. Писал Гаврила Петров.

Помета: За писмо 5 алтын, от записки гривна. Прием Феофанов, подпись февраля в 25 день. Вершина за подписанием Алексея Протопопова (с.146)

№ 398. Запись сговорной-рядной (...).

Генваря в 29-й день. Стольник Гаврило Матвеев сын Пестов зговорил сестру свою девицу Василису Матвееву дочь замуж за жильца за Данилу Васильева сына Иванова с приданным на сто рублев и с вотчинною. Свидетели: московский дворянин Алексей Иванов сын Лихарев, стряпчий Савва Прокофьев сын Арцыбушев - сами руки приложили. Писал Михайла Булахов.

Помета: За писмо шесть алтын четыре денги взято. Записана генваря в зо-й день (c.410).

Следует пояснить, что перед нами не подлинники, а их сокращенные записи в регистрационные книги документов, называвшиеся «крепостными книгами» (от слова «крепость» - договор). Они велись Крепостной конторой при Юстицколлегии. В редких случаях документ копировался в книгу целиком, обычно он помещался туда в сильно сокращенном виде. Запись в книгу, заверенная свидетелями, имела нотариальное значение, к ней обращались при возникновении судебных споров, подлинники же возвращались в руки владельцев. 
Публикация этих документов в недавно вышедшей книге «Дворяне Москвы: свадебные акты и духовные завещания петровского времени» начинается с двух статей, носящих источниковедческий характер (автор - Н.В. Козлова). Они чрезвычайно важны для тех, кто будет иметь намерение серьезно работать с подобными актами, и интересны для тех, кто заглянет в них любопытства ради. В первой статье «Археографическая характеристика документов» рассказывается о том, как проходила работа по выборке материалов из фондов Юстиц-коллегии (РГАДА. Ф.282, 285), содержащих 24 тыс. единиц хранения, какие задачи решались и какие трудности стояли перед составителями. Автор дает подробнейший археографический обзор публикуемых завещаний, рядных и сговорных документов: как составлялись записи, какую смысловую структуру они имели, как подписывались и регистрировались, как датировались, а также - как хранились и использовались записные книги и многое другое. Во второй статье - «Историкодипломатическая характеристика семейно-правовых актов...» - Н.В. Козлова осуществляет типовую характеристику документов. Она «расчленяет» их на смысловые части и раскрывает их назначение. В завещаниях это хорошо известные пять клаузул (частей), традиционно определяемых латинскими терминами риторики: invocatio, intitulatio, arenga, dispositio, sanctio ${ }^{1}$. Автор показывает изменчивую дипломатику сговорных и рядных записей.

Следует признать, что исследователи, работающие в архивах, крайне редко заглядывают в такие фонды как крепостные конторы. Их документы многим кажутся скучной бюрократической писаниной по малозначащим для «большой истории» поводам. Но и те, кто знает им цену, хорошо осознают, что найти интересующее тебя историческое лицо или определенные факты в огромной массе этих актов дело очень трудоемкое и часто - безнадежное. Только исследователь, умеющий глубоко прочувствовать поэтику бюрократического текста, может уделить им свои время и труд. И вот, авторы-составители новой книги подносят историкам на блюдечке с золотой каемочкой 888 актов (326 завещаний, 499 сговорных, 63 рядных записей) и прилагающийся к ним обширный аналитикосправочный аппарат! В последний входят: Вводный раздел, состоящий из Предисловия и четырех исследовательских статей (две из которых я уже упомянула выше); перечень заголовков актов, сделанный в хронологическом порядке; комментарии к документам; большое количество цветных иллюстраций; именной и географический указатели; терминологический словарь; хронологическая таблица. Такая оснащенность книги справочными и дополнительными материалами делает ее использование удобным, информативным и приятным.

Рецензируемая книга, однако, не является первым опытом публикации частноправовых актов Крепостной конторы. Она продолжает издание аналогичных документов, начатое профессором МГУ Н.В. Козловой в издании «Городская семья XVIII века. Семейно-правовые акты купцов и разночинцев Москвы» ${ }^{2}$ которое увидело свет 13 лет тому назад. Дополнение купеческих материалов ${ }^{3}$ документами,

\footnotetext{
${ }^{1}$ К сожалению, в книге эти термины написаны ошибочно: очевидно, что компьютер исправил латынь на английский вариант с окончанием «tion» (это же произошло и с моим текстом в этих же словах при написании данной рецензии), и это осталось незамеченным при редактуре. (C . 22).

${ }^{2}$ Городская семья XVIII века. Семейно-правовые акты купцов и разночинцев Москвы. Составление, вводная статья и комментарии Н.В.Козловой. М., 2002.

3 Анализу купеческих документов посвящена вся обширная рецензия американского исследователя Даниила Кайзера на публикацию Н.В. Козловой «Городская семья..»: Daniel H. Kaiser. Review of Nataliia Vadimovna Kozlova, ed., Gorodskaia sem'ia XVIII veka: Semeinopravovye akty kuptsov $i$
} 
вышедшими из дворянской среды, позволяет теперь надеться на появление серьезных сравнительных исследований в области частной, экономической, социальной и духовной жизни людей петровского времени.

Частноправовые акты как источник пока малоизвестны и плохо осмыслены. Они - прошедшие через суровое бюрократическое редактирование «бедные родственники» в семье источников личного происхождения. Они несравнимы с дневниками, письмами, мемуарами, насыщенными эмоциями и размышлениями, но у них есть свои преимущества. Актов - очень много, в то время как дневников и мемуаров для российского XVIII века ничтожно мало. Своей специфической информативностью, отсутствующей в других текстах, частноправовые акты имеют возможность восстанавливать зыбкий образ минувшего бытия. За каждым из этих бюрократических по форме текстов стоит составивший его человек: его собственные позиции по вопросу вступления в брак, его предсмертные распоряжения, его семейные, дружественные, служебные связи. Безусловно, на решения людей при написании документа оказывало влияние, помимо личных обстоятельств, и действующее юридическое право, соблюдение которого в официальных документах контролировалось. Так, в 1714 г. было принято новое законодательство по наследственному праву (указ «о единонаследии»): в нем традиционный равный раздел наследства между детьми заменялся на передачу родителями всей недвижимости лишь одному из них. Тексты завещаний фиксируют его исполнение. Но не менее явно они же воспроизводят и завуалированные действия по уклонению от этого закона, ибо он не вызвал поддержки дворянства, посчитавшего указ несправедливым. Как пишет Н.В. Козлова, документы помогают «выявить те средства и ухищрения, к которым прибегали дворяне, а также представители купеческо-разночинской среды, чтобы не нарушая явно, все же обойти нормы, установленные законом. Их обобщение дает возможность судить о степени распространения скрытого сопротивления правительственной мере, а следовательно, понять ту 'стратегию поведения', которая формировалась...в ответ на введение властью новации» (с. 61). Проиллюстрирую это примером. Стольник И.Р. Стрешнев в 1722 г. в соответствии с указом 1714 г. о единонаследии завещал всю недвижимость старшему сыну Василию. Младшим же сыновьям Петру и Николаю - по 8 тысяч руб., старшей замужней дочери - 3 тыс. руб., а младшей незамужней - 9 тыс. руб. Всего 28 тыс. руб. (с.325-326). Такая астрономическая сумма, безусловно, была собрана отцом от продажи земельных имений и завещана детям на покупку таковых же. Старшая дочь ранее получила приданное, потому ей завещано только 3 тыс. руб. В итоге все дети наделены поровну, как и требовало обычное право и понимание справедливости: таким образом, и указ 1714 г. оказался формально соблюден и обычай не нарушен.

В биографическом аспекте работа с опубликованными в книге документами и сложна, и увлекательна. Возможно ли сказать что-либо значимое о людях, пришедших нотариально заверить свои документы в Московскую крепостную контору, притом, что, кроме текста этих документов, нам о них более ничего неизвестно? Для этого необходимо получить дополнительные сведения, и это можно сделать уже в рамках данной книги, используя ее справочный аппарат.

raznochintsev Moskvy [The 18th-Century Urban Family: Legal Documents of Moscow Merchant and Professional Families].6o8 pp. Moscow, 2002. // Kritika: Explorations in Russian and Eurasian History 5:4 (Fall 2004): 779-790. Его статья Gender, Property, and Testamentary Behavior: Eighteenth-Century Moscow Wills // Harvard Ukrainian Studies 28, nos. 1-4 (2006) также написана с использованием вышеуказанной публикации документов. 
Опубликованные документы пестрят дворянскими фамилиями, прославленными в российской истории и культуре (это, например, кн. Пожарские, кн. Одоевские, кн. Долгорукие, Татищевы, кн. Вяземские, кн. Волконские, кн. Юсуповы, кн. Урусовы, Раевские, Суворовы, Шереметевы и другие), имеющими богатые родословные и даже личные архивы. Из них возможно почерпнуть сведения, проясняющие актовый документ, и - наоборот - пополнить историю этих именитых фамилий новыми фактами. Перелистывая страницы издания, видишь, как происходит смена поколений, отраженная в текстах петровского времени: еще встречаются представители старых боярских родов, но их дети уже просватаны и связаны с другими, новыми, фамилиями, они станут известны в будущем как политики, как воины, как деятели культуры. Частноправовые акты раскрывают девичьи фамилии знатных женщин, обычно неизвестные, но, помимо этого, женщины хорошо представлены как самостоятельные акторы в семейных вопросах.

В целом в книгу вошло огромное количество имен, о чем свидетельствует многостраничный именной указатель. Он чудесным образом собирает вместе людей одной фамилии, документы которой разбросаны по разным годам и разным книгам, а также различные акты вокруг одного лица. Именно указатель раскрывают в первую очередь практикующие историки, ибо у каждого из них есть излюбленные ими персоны прошлого, для биографий которых издание дает надежду на их пополнение новыми данными. Я видела, как на презентациях данной книги историки выхватывали ее друг у друга из рук и начинали в ней самозабвенно рыться, более не обращая ни на кого внимания. Очевидно, что ими двигало непреодолимое желание найти какие-либо сведения о «своих» героях. Я и сама не осталась от этого в стороне. Например, одна из интересующих меня личностей XVIII века - академический переводчик Сергей Саввич Волчков. Смотрю именной указатель - есть Волчковы! К сожалению, среди них нет Сергея, зато имеется Савва - его отец. Обращаюсь к документу - сговорной грамоте. В ней Савва Михайлов сын Волчков обозначен среди свидетелей. По происхождению он дворянин, но, оказывается, служил стряпчим у царицы Екатерины Алексеевны (№ 737). Ищу дальше - и нахожу, что ранее он был стряпчим у царицы Марфы Матвеевны Апраксиной (№ 516). Стряпчий того времени - это грамотей и знаток законов. Служба отца многое прояснила мне в жизни его сына: стало понятным, почему Сергей получил прекрасное заграничное образование, откуда он хорошо знал дворцовый обиход. Таких небольших, но важных находок, работая с данной публикацией, можно сделать бессчетное количество, поэтому историкам от нее трудно оторваться.

Однако большинство фамилий, упомянутых в документах, принадлежат пока совершенно неизвестным в истории людям. Без дополнительных исследований такой документ остается в той же степени молчалив, в какой - старая фотография без подписи. Чем же информативны эти акты? Безусловно, не биографической информацией. Сведенные вместе в одну публикацию, они, дополняя друг друга, в целом обогащают наши познания о разных сторонах жизни петровской эпохи и ее людях. Авторы-составители публикации в процессе работы сами выделили несколько исследовательских направлений, разработку которых представили в статьях Вводного раздела.

А.Ю. Прокофьева рассмотрела внутрисемейные и межличностные отношения в дворянской среде. Действительно, тексты завещаний насыщены информацией о семейных и дружеских отношениях. К сожалению, в данном случае материал 
ограничен тем, что опубликованы не сами тексты завещаний, а их краткое изложение в записных книгах. Текст в процессе записи в книгу сокращался в первую очередь за счет пассажей, отражавших эмоциональный настрой завещателя, за счет наставлений домочадцам и т.д. В результате наблюдения автора сводятся к тому, что были семьи счастливые и несчастные, дружные и недружные. В статье поставлено много интересных вопросов, на которые автор пока не находит ответа.

Н.В. Козлова обратилась к информативному потенциалу семейно-правовых актов с точки зрения социальной истории. Сплошной просмотр (а точнее - въедливое прочтение) документов дали ей возможность вычленить группы однотипных смысловых фрагментов, приводящих к определенным наблюдениям над особенностями жизни людей петровского времени. Перекрестная же информация документов раскрыла «характер отношений, существовавших между людьми разного статуса и положения на персональном уровне» (с. 50). На нескольких примерах использования такой перекрестной информации автору блестяще удалось выделить круг приятелей (двух дьяков, боярского человека и фискала), имевших тесные личные и деловые связи (с. 48-49). Важные наблюдения сделаны Натальей Вадимовной над тем, как люди определяли свой социальный статус (с.50-51). Это требует объяснения. Стройную иерархию чинов допетровской Московии (бояре, окольничие, думные дворяне, думные дьяки, стольники, спальники, московские дворяне и т.д.) разрушили реформы Петра, в результате которых были введены новые военные и штатские чины и новые должности. При этом старые чины никто не отменял. Именно в частноправовых актах люди именовали себя так, как они сами считали нужным и «указывали те чины и в том порядке, которые, по их мнению, в лучшей степени отражали присущий им социальный статус. Иной раз старый чин (...) соседствовал с новым, давая сочетания типа «стольник-полковник» (с.510). Не без труда записывались в Крепостной конторе такие новые названия должностей как, например, «эквипажемейстер» (c.187) или «императорского величества контерфектер» (с. 556). Исследовательница ставит в статье проблему брачных стратегий разных социальных групп, которые, при слабой разработанности в российской историографии истории семьи (Family history), практически не изучены. Она очерчивает различные варианты решения имущественных вопросов, отраженные в завещаниях. Вопрос о службе рядовых дворян также рассмотрен Н.В. Козловой через призму завещаний. В целом они воссоздают картину того, как большинство военных людей теряли на государевой службе здоровье, силы и нажитое имущество, а приобретали большое количество долгов, с которыми стремились расплатиться уже посмертно (с. 52-54). Чрезвычайно существенным мне представляется выделение Н.В. Козловой из массы людей разных чинов группы лиц, которую можно определить как «служители» при вельможах. Некоторые из них и ранее были известны по нескольким биографиям деятелей петровского времени, ибо в это время из «служителей» (которые фактически принадлежали к категории дворовых людей) можно было выбиться в люди государственного значения (например, таковыми были канцлер П.П. Шафиров или прибыльщики В.С. Ершов и А.А. Курбатов). Однако частноправовые акты показывают, что такие лица (управляющие, дворецкие, камердинеры, деловые люди и др., не пробившиеся в государственную службу, а остававшиеся при своих хозяевах) составляли особую социальную группу, они владели немалым движимым имуществом и даже покупали московские дворы и деревни с крепостными (с.56-57).

Вступительные статьи Вводного раздела имеют хорошо оправданную цель указать читателям на наиболее яркую информацию источников, полученную в 
процессе подготовки публикации. При этом авторы оставляют в стороне исследовательскую литературу по рассматриваемым вопросам, затрагивая ее лишь в малой степени. Труды Daniel Kaiser - исследователя, наиболее активно работающего в области истории русской городской семьи XVII - XVIII вв. с использованием частноправовых актов, авторами рецензируемой книги даже не упоминаются, как не упоминается и книга Мишель Маррезе «Бабье царство»: дворянки и владение имуществом в России (1700-1861 г.). М., 2009), прямо связанная с рассматриваемыми вопросами завещательной политики. Мне представляется, что исследовательская литература могла бы быть представлена в статьях более широко. Вступительный раздел «замкнут на самом себе» также и в отношении использования других источников в сравнительном плане. Например, напрашиваются сравнения с завещаниями и свадебными актами допетровского времени. Исключение составляет частое обращение Н.В. Козловой к письмам и запискам дипломата петровского времени кн. Б.И. Куракина. Оно сразу обогащает текст и ясно показывает, что семейно-правовые акты в дальнейшем не могут изучаться изолированно, а должны быть помещены в широкой контекст документов разного происхождения петровской эпохи. Авторы вводных статей отнюдь не стремились поставить, а тем более решить все вопросы, встающие при изучении частноправовых актов. Вступительные статьи предназначены стать неким опорным фундаментом для дальнейших изысканий, авторы не раз повторяют, что многое еще «предстоит выяснить» будущим исследователям, что «круг сюжетов социальной истории России петровского времени, информация о которых содержится в семейно-правовых актах.... может быть значительно расширен» (с.64).

Действительно, позволю себе отметить еще несколько тематических областей, замеченных мной в ходе знакомства с книгой. Так, например, документы косвенным образом воссоздают облик Москвы петровского времени: в них упоминается множество московских храмов, монастырей, улиц, переулков и слобод, на которых находились те или иные дворы, а в дворах - каменные палаты. Отмечаются общественные места - например, местоположение торговых бань (в приходе церкви Николая Чудотворца в Кузнецкой слободе (с.157)). Писцы Московской крепостной конторы осваивали названия новых московских учреждений, в первую очередь - учебных, в связи с появлением новой социальной группы - «школьников». «Ученик латинских школ» (с.583), «школьник Академии школьного учения» (с.555), «школьник Спасских школ Латынских наук» (с.6о6-507), «ассистент Славяно-латинской академии» (с.516) - это все ученики Славяно-греколатинской академии на Никольской улице, а вот «математических наук ученик» и «школьник альтирельной (так! - О.К.) школы что в Москве» определенно учились в школе Математических и Навигацких наук в Сухаревской башне (c. 516, 553).

Опубликованные акты отразили разные стороны духовной и материальной культуры петровского времени. Часто встречающиеся перечни икон, которыми авторы завещаний благословляли своих близких, хорошо воссоздают репертуар иконописных образов, находившихся в московских домах, и убранство их окладов. Но важно не только это: иконами благословляли родню не просто так, а со смыслом. В воспоминаниях тот же кн. Б.И. Куракин писал: «Имел я отца бо̀льшую любовь пред другими детьми. И на память той милости, при конце живота, благословил образ Спасителев Нерукотворенного, которым его благословил также 
отец, а мой дед» ${ }^{4}$. Следовательно порядок благословения иконами являл личный выбор завещателя и отражал его отношение к своим близким. Асессор Дружинин, завещая своим домочадцам каждому по иконе из своего домашнего иконостаса, просил их «того иконостаса не разбирать, и икон святых не вынимать, а молитца им всем вопче, как при мне было, будучи в одном моем доме» (с.295).

Хоть и не часто, но в завещаниях упоминаются книги. Так, полковник Стремоухов завещал двум внучкам-девкам Авдотье и Анне книги: «Библия полуустав, Триодь, Октай, Тестомент, Жития святых литовской печати, Канонник, Патерик печерский, Псалтырь, два Часослова» (с.154) - вполне традиционный набор для книжников допетровской Руси.

Важной информацией, содержащейся в частноправовых актах, является грамотность москвичей, поскольку каждый из документов содержит много подписей. Далеко не во всех случаях по записи в регистрационной книге ясно, кто из свидетелей сам «руку приложил», а за кого расписались другие, но в отношении авторов духовных, рядных и сговорных грамот это обычно указывалось точно: «сам руку приложил», «подписал своею рукою» или «вместо такого-то руку приложил такой-то».

Особо следует сказать о комментариях к документам, именно они заставляют многие из текстов «заговорить». Комментарии - разные: и биографического характера, и разъясняющие контекст создания определенного акта, и отсылающие к другим документам, связанным с комментируемым. Некоторые из них состоят из пары строк, другие занимают несколько страниц и по сути являются самостоятельным исследованием. Так в комментарии к документу № 300 Духовной подполковника С.М. Голенищева-Кутузова - на четырех станицах (мелким петитом) рассказывается захватывающая история опротестования этого завещания родственниками (с.764-767), для воссоздания которой были привлечены судебные дела других фондов. В комментарии к делу № 219 подробно раскрыта семейная история купцов Бориных (с.753-755). Такие существенные комментарии рождаются тогда, когда публикацией источников занят историк-исследователь, который не в силах отказать себе в удовольствии не только опубликовать документ, но и полностью раскрыть его контекст. Однако к некоторым документам комментарии отсутствуют. В основном это обоснованное молчание, но иногда об упоминаемых фамилиях все же сказать было бы не лишним (например, Иван Родионович Стрешнев, Матвей Андреевич Виниус, Венедикт Борисович Змеев являлись потомками очень известных деятелей XVII в.).

Отбор документов производился авторами на основе их принадлежности дворянству. В связи с этим не совсем понятно, как в эту выборку попал истопник, сосватавший свою дочь за церковного дьячка (№ 379. с.404), а также на каком основании к дворянам причислен некий Гаврила Колесницкий - в его духовной нет ни одного намека на дворянское происхождение, а владение единственным двором в Кузнецкой слободе скорее говорит о том, что он был посадским человеком (с.157). А вот Андрею Федоровичу Нарышкину и его сыну Андрею составители присвоили по недоразумению княжеский титул, в то время как род Нарышкиных княжеским никогда не являлся (c.103, 549, 853). «Патриарша дому дворянин» Иван Серков (с.191) в именном указателе назван дворянином, в то время как «патриаршие дворяне» и светские дворяне - это совершенно разные социальные группы. Подобные неточности на 910 страницах книги встречаются редко - в целом это прекрасно

\footnotetext{
${ }^{4}$ Vita del Principe Boris Kourakin //Архив кн. Ф.А. Куракина. Саратов. 1890. Т. 1. С. 248.
} 
подготовленное и качественно оформленное издание, сделанное ценою упорного труда многих лет. В заключении все же отмечу, что богатство материалов Юстицколлегии далеко не исчерпано двумя обширными публикациями документов Московской крепостной конторы: не менее объемен и значим аналогичный фонд Санкт-петербургской крепостной конторы, который ждет своих публикаторов. 